\title{
Design of Power Cable UAV Intelligent Patrol System Based on Adaptive Kalman Filter Fuzzy PID Control
}

\author{
Siyu $\mathrm{Chen}^{1}$, and $\mathrm{Wei} \mathrm{Chen}^{2 *}$ \\ ${ }^{1}$ School of Electric Power Engineering, Nanjing Institute of Technology, Jiangning District, Nanjing, 211167, China. \\ ${ }^{2}$ Industrial Center, Nanjing Institute of Technology, Jiangning District, Nanjing, China \\ *Corresponding author chenwei-nj@163.com
}

\begin{abstract}
Patrol UAV has poor aerial posture stability and is largely affected by anthropic factors, which lead to some shortages such as low power cable tracking precision, captured image loss and inconvenient temperature measurement, etc. In order to solve these disadvantages, this article puts forward a power cable intelligent patrol system. The core innovation of the system is a $360^{\circ}$ platform. This collects the position information of power cables by using far infrared sensors and carries out real-time all-direction adjustment of UAV lifting platform through the adaptive Kalman filter fuzzy PID control algorithm, so that the precise tracking of power cables is achieved. An intelligent patrol system is established to detect the faults more accurately, so that a high intelligence degree of power cable patrol system is realized.
\end{abstract}

Keywords. Adaptive Kalman filter; Fuzzy PID; Power cable; UAV; Intelligent patrol.

\section{Introduction}

Modern cities and enterprises all use the power cables for power transmission and distribution, and power transmission and distribution quality is affected by the running states of power cables. In order to improve power supply reliability and predict failure, cable temperature is a key indicator for fast judgment of fault points. Current power supply systems mostly adopt temperature patrol to realize fast troubleshooting, including overload, short circuit and aging, etc.

In traditional power line patrol process, patrol work is carried out by workers and patrol conditions are recorded in paper sheets, and then the patrol conditions will be input into the computer. Therefore, the patrol data is affected by human factors; meanwhile. Whether the workers patrol the whole line cannot be effectively managed, patrol quality cannot be ensured, and the safety conditions of power lines cannot be guaranteed, which leaves security risks. Then, what kind of effective measures can be taken becomes a difficult problem for the power sector. Therefore, the development of a temperature measurement system, which is safe and stable and has wide application, has a great significance to ensure the safe operation of power grid; this temperature measurement system can monitor the running temperatures of key points of the equipment in a real-time manner, grasp the running status, timely find out hidden faults, take corresponding measures and prevent further expanding of accidents[1].

Patrol UAV has poor aerial posture stability and is largely affected by anthropic factors, which lead to some shortages such as low power cable tracking precision, captured image loss and inconvenient temperature measurement, etc. In order to solve these disadvantages, this article puts forward a power cable intelligent patrol system developed based on adaptive Kalman filter fuzzy PID control algorithm. This system collects the position information of power cables by using far infrared sensors and carries out real-time all-direction adjustment of UAV lifting platform through the control algorithm, so that the precise tracking of power cables is achieve. This system uses STM32 as the control platform, uses GPS module to collect geographic information of power cables, uses temperature logger to collect temperature data of power cables and uses camera to capture image data; an intelligent patrol system is established to detect the faults more accurately, so that a high intelligence degree of power cable patrol system is realized. This system can directly display whether the power lines are patrolled and whether the patrol work has been completely finished, so as to meet the requirements of power line patrol in speed, efficiency and timeliness; it improves the power line patrol management to a new level and realizes the electronization, informationization and intelligence of patrol work, so as to guarantee the high efficiency, low failure rate and safe operation of power system[2].

\section{System configuration}

System configuration diagram is shown in figure 1: 


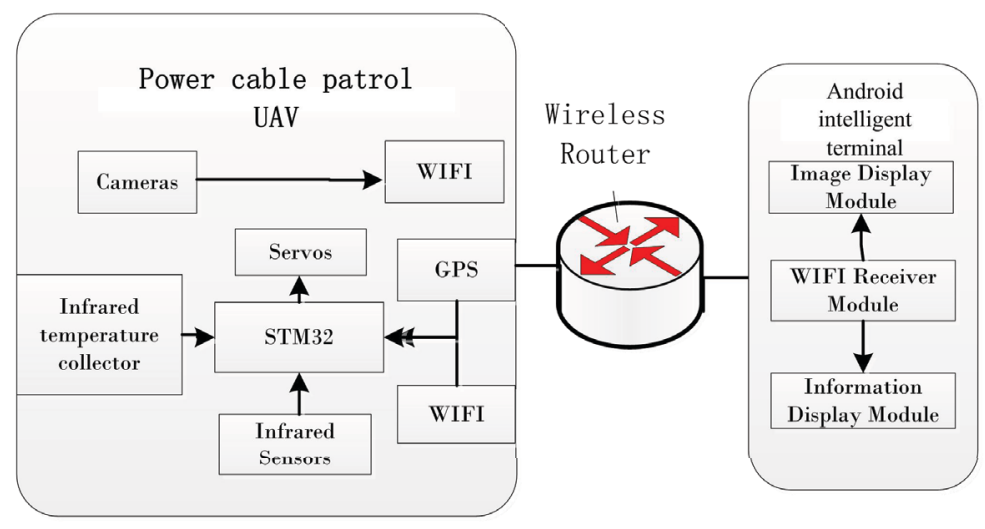

Figure 1. System configuration diagram

The whole system mainly consists of the power cable patrol UAV and an Andriod intelligent handheld terminal.

(1) Power cable patrol UAV: Patrol workers carry out rough patrols by means of remote control. The far infrared sensor on lifting platform acquires cable position information and controls the platform steering engine, so as to accurately capture power cables; temperature acquisition module on the platform is responsible for temperature collection; the camera acquires image information, realizing the monitoring on the waste, oil pollutant and other faults on power cables; the wireless router is used for data transmission and exchange.

(2) Android intelligent terminal: The intelligent Android mobile terminal, which is developed based on Android mobile platform and combines image and information display modules, can realize the integration of image transmission, temperature, geographic coordinates and time information, and it can monitor the patrol images and information in real-time manner.

\section{Design of key structures of power cable patrol uav}

Sensor Selection. Long-distance infrared sensor: As cable transmission will generate heat, the long-term allowable working temperature of power cable core is $70^{\circ} \mathrm{C} \sim 90^{\circ} \mathrm{C}$, and the temperature of insulation layer is $20^{\circ} \mathrm{C}$ to $40^{\circ} \mathrm{C}$ different from cable core. The temperature of external insulation layer is at least $30^{\circ} \mathrm{C}$ according to the calculation. Considering the influence of environment temperature and the cable temperature is much higher than the environment temperature, the infrared wavelength of power cable is shorter than those of the surrounding environment. The measuring range of long-distance infrared sensor is 0 to 8 meters, meeting requirement of actual flying height[3].

Infrared temperature sensor: SMTIR99XX series are thermopile-based silicon infrared sensors which can measure temperatures in contactless ways; as infrared radiation characteristics are related to temperature, filters can be used to measure different temperature ranges. Mature semiconductor process can reduce the cost and miniaturize the overall dimension at the same time. In order to meet the requirements of some certain applications, the opening angle of infrared sensor can be designed to be less than $7^{\circ}$. Based on the Seebeck Effect, the temperature difference can be calculated according to the analog output from infrared sensor; SMT9902 is equipped with a built-in temperature sensor which can measure the temperature of its cold end, based on which the temperature of the object to be measured can be obtained through calculation. The working temperature of the sensor itself is -40 to $100^{\circ} \mathrm{C}$. TO05 packaging is adopted for the sensor, and it has high precision, high sensitivity $(110 \mathrm{~V} / \mathrm{W})$, low impedance and a measuring temperature range from -100 to $2000^{\circ} \mathrm{C}$.

Software Design. The software system flow chart of UAV patrol system is shown in Figure 2:

The main program of the temperature acquisition module is as shown in Figure 3: 


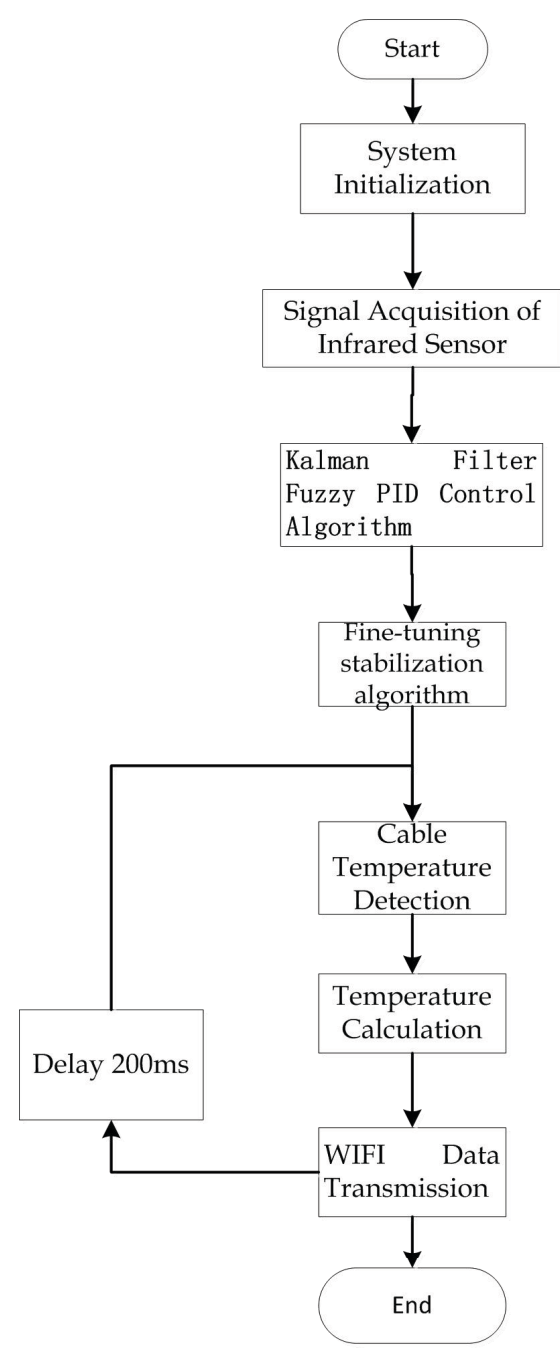

Figure 2: Software system flow chart

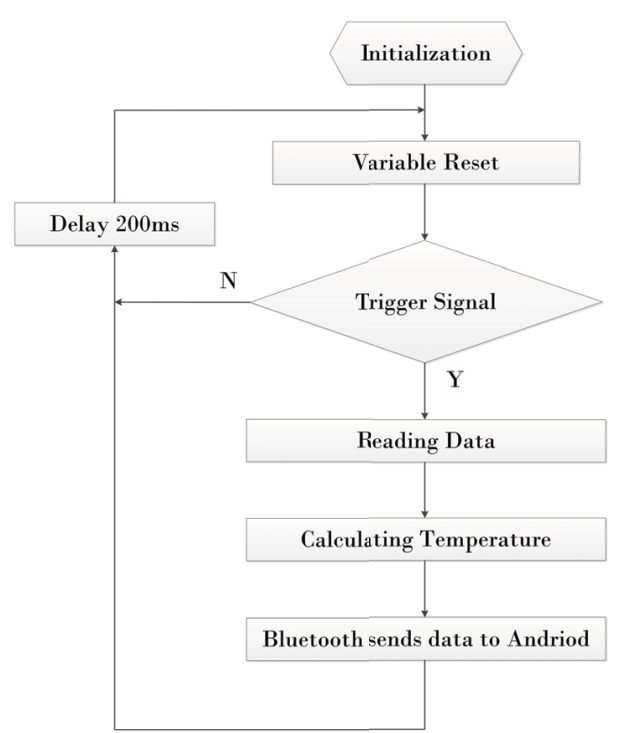

Figure 3: Flow chart of temperature acquisition modul

In the process of initialization, the definition of variables and the settings of ports and baud rate are completed. The program continuously detect whether there is a trigger signal, and only when it detects the trigger signal, will it drive SMT9902 to start temperature measurement and read temperature data. The temperature data in SMT9902 can be divided into high byte $(\mathrm{DataH})$ and the low byte (DataL), and the actual Celsius temperature can be obtained after a certain amount of calculation on the two bytes, and the calculation formula is as follows:

Data $=[($ DataH \& $0 X 007 F)<<8]+$ DataL

TempData $=[($ Data $\times 0.02)-0.01]-273.15$

After obtaining the Celsius temperature, it will initiate the WIFI module transmission program, and as Bluetooth module are in series connection with Arduino, Bluetooth transmission program is the same like serial port output program[4]. 


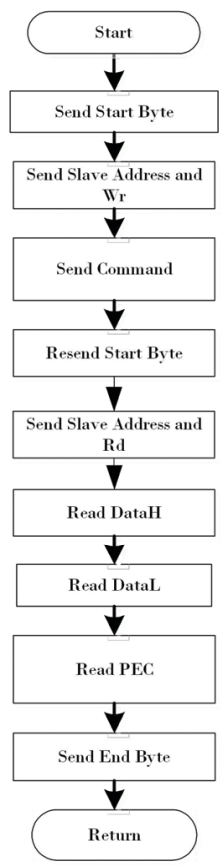

Figure 4. Data read flow chart

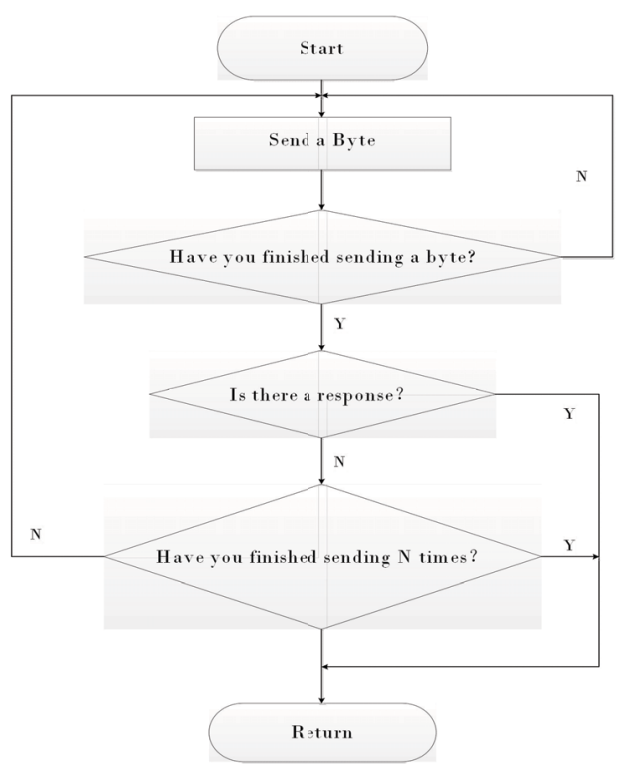

Figure 5. Operation process of each byte of data

Several SMT9902 can be used in one system, and different addresses are used to separate the components. Therefore, in a multiple SMT9902 system, each SMT9902 need to be allocated with an address, and the default address for components is 5AH. Data read procedures are shown in Figure 4. The data read from SMT9902 is in byte, and the operation procedures for each byte of data are shown in Figure 5. Each time only one byte (in bits, and 8 bits form one byte) is sent, then it will judge whether there is any response, and if there is a response, the next byte will be sent; if no, this byte will be sent repeatedly until there is a response, and if there is no response after repeating sending the same byte for a couple of times, the will come to an end[5].

\section{Fuzzy pid control algorithm based on adaptive kalman filter}

This article puts forward a fuzzy PID control algorithm that based on adaptive Kalman filter; carry out self-learning and self-tuning for PID parameters ${ }^{k_{\mathrm{p}}}, k_{\mathrm{i}}$ and $k_{\mathrm{d}}$, to find out the best combination, and meanwhile it can control interference noise and measurement noise to reach the filtering effect.

The control structure is as shown in Figure 6[6]:

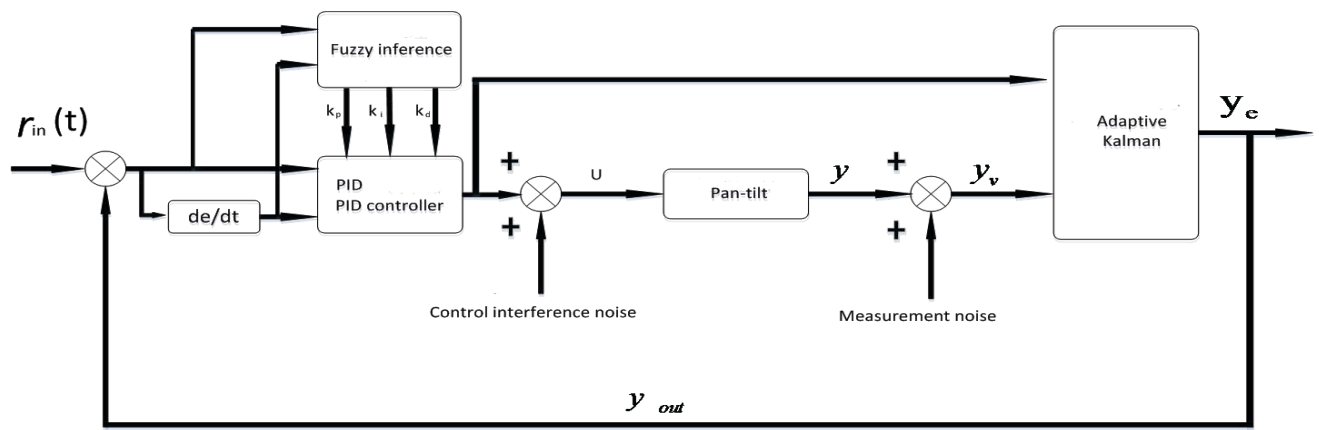

Figure 6: Structural diagram of fuzzy PID control algorithm based on adaptive Kalman filter

Fuzzy Adaptive Setting PID. The setting of PID parameters is a key problem in PID control. However, in actual applications, most industrial processes have different degrees of nonlinear, parameter time-varying and model uncertainty; therefore, the general PID control cannot realize the accurate control of such processes. 
Fuzzy adaptive PID control adopts the basic theory and method of fuzzy mathematics, and uses fuzzy set to express the conditions and operations of the rules, and it stores these fuzzy control rules and relevant information (such as evaluation indicator and initial PID parameters, etc.) into the computer knowledge base, then the computer will automatically realize the best adjustment of PID parameters by means of fuzzy reasoning according to the actual response conditions of the control system.

PID controller is a linear controller, it makes up the control deviation according to this fixed value:

$r(t)$ and actual output value $\mathrm{y}(\mathrm{t})$

$e(t)=r(t)-y(t)$

The continuous conditions of PID control law:

$u(t)=k_{p}\left[e(t)+\frac{1}{T_{I}} \int_{0}^{t} e(t) d t+T_{D} \frac{d e(t)}{d t}\right]$

where, ${ }^{k_{p}}$ is the scale factor; $T_{I}$ is the integral time constant; $T_{D}$ is derivative time constant

Discrete conditions:

PID parameters fuzzy self-setting functions by finding out the fuzzy relationship among three PID parameters

$u(k)=k_{p}\left\{e(k)+\frac{1}{T_{I}} \sum_{j=0}^{k} T e(j)+T_{D} \frac{e(k)-e(k-1)}{T}\right\}$

$\Delta u(k)=k_{p}(e(k)-e(k-1))+k_{i} e(k)$

$+k_{d}(e(k)-2 e(k-1)+e(k-2))$

and $e_{\text {and }} e_{c}$. It continuously detect $e_{\text {and }} e_{c}$, and make online adjustment on the three parameters according to fuzzy control law to meet the different requirements of $e_{\text {and }} e_{c}$ on control parameters, so that the objectives can have better dynamic and static performances, as shown in Table 1.

Table 1: The relationship between PID control parameters with system performance index in time domain

\begin{tabular}{|l|l|l|l|l|}
\hline Parameter name & Rising time & Overshoot & Transient time & Static error \\
\hline \hline$k_{p}$ & Reduce & Increase & Minor change & Reduce \\
\hline$k_{i}$ & Reduce & Increase & Increase & Eliminate \\
\hline$k_{d}$ & Minor change & Reduce & Reduce & Minor change \\
\hline
\end{tabular}

In the quantitative field of input language variables: take 7 fuzzy subsets $\{$ NB NM PS PM PB NS Z\}, which are Negative big, Negative middle, Negative small, Zero, Positive small, Positive middle and positive big, respectively.

Corresponding to the error $e$ and error change rate $e_{c}, 7$ degrees are quantified as $\{-3,-2,-1,0,1,2,3\}$. Then, the membership grade of fuzzy subsets are determined, then design PID parameters according to membership grade assignment table of each fuzzy subset and fuzzy control model of each control parameter and based on fuzzy synthesized inference, then the fuzzy control tables for setting the three parameters ${ }^{k_{p}}, k_{i}$ and ${ }^{k_{d}}$ are obtained, as shown in Table 2, 3 and $4[7]$.

Table 2: Fuzzy rule table of $k_{p}$

\begin{tabular}{|l|l|l|l|l|l|l|l|}
\hline $\begin{array}{l}\text { ec } \\
\text { NB }\end{array}$ & NB & PB & PB & ZO & PS & PM & PB \\
\hline NM & PB & PB & PM & PS & PS & ZO & NS \\
\hline NS & PM & PM & PM & PS & ZO & NS & NS \\
\hline ZO & PM & PM & PS & ZO & NS & NM & NM \\
\hline PS & PS & PS & ZO & NS & NS & NM & NM \\
\hline
\end{tabular}




\begin{tabular}{|l|l|l|l|l|l|l|l|}
\hline PM & PS & ZO & NS & NM & NM & NM & NB \\
\hline PB & ZO & ZO & NM & NM & NM & NB & NB \\
\hline
\end{tabular}

Table 3: Fuzzy rule table of $k_{i}$

\begin{tabular}{|l|l|l|l|l|l|l|l|}
\hline ec & NB & NM & NS & ZO & PS & PM & PB \\
\hline NB & NB & NB & NM & NM & NS & ZO & ZO \\
\hline NM & NB & NB & NM & NS & NS & ZO & ZO \\
\hline NS & NB & NM & NS & NS & ZO & PS & PS \\
\hline ZO & NM & NM & NS & ZO & PS & PM & PM \\
\hline PS & NM & NS & ZO & PS & PS & PM & PB \\
\hline PM & ZO & ZO & PS & PS & PM & PB & PB \\
\hline \hline PB & ZO & ZO & PS & PM & PM & PB & PB \\
\hline
\end{tabular}

Table 4: Fuzzy rule table of $k_{d}$

\begin{tabular}{|l|l|l|l|l|l|l|l|}
\hline ec & NB & NM & NS & ZO & PS & PM & PB \\
\hline NB & PS & NS & NB & NB & NB & NM & PS \\
\hline NM & PS & NS & NB & NM & NM & NS & ZO \\
\hline NS & ZO & NS & NM & NM & NS & NS & ZO \\
\hline ZO & ZO & NS & NS & NS & NS & NS & ZO \\
\hline PS & ZO & ZO & ZO & ZO & ZO & ZO & ZO \\
\hline PM & PB & NS & PS & PS & PS & PS & PB \\
\hline \hline PB & PB & PM & PM & PM & PS & PS & PB \\
\hline
\end{tabular}

Adaptive Kalman Filtering. Because the lifting platform of UAV patrol system can be affected by various environmental factors, adaptive Kalman filter is used in this paper to suppress interference noise and measure the noise so as to improve the control accuracy.

The state equation and measurement equation of the system discrete model are: $\mathrm{X}(\mathrm{k}+1)=\Phi$ $(\mathrm{k}+1, \mathrm{k}) \mathrm{X}(\mathrm{k})+\mathrm{B}(\mathrm{k}) \mathrm{U}(\mathrm{k})+\mathrm{W}(\mathrm{k}), \mathrm{y}^{v}(\mathrm{k}+1)=\mathrm{HX}(\mathrm{k}+1)+\mathrm{V}(\mathrm{k})$, of which $\mathrm{X}(\mathrm{k})$ is the state matrix, $\mathrm{y}(\mathrm{k})$ is the measurement matrix, $\mathrm{U}(\mathrm{k})$ is the control output, $\Phi$ is the state transfer matrix, B is the input matrix, $\mathrm{H}$ is measurement transfer matrix, $\mathrm{W}(\mathrm{k})$ and $\mathrm{V}(\mathrm{k})$ respectively control the interference noise and measurement noise. The noise statistics are: $\mathrm{E}\{\mathrm{W}(\mathrm{k})\}=\mathrm{q}, \mathrm{E}\{\mathrm{W}(\mathrm{k}) \mathrm{W}(\mathrm{j})\}=\mathrm{Q}(\mathrm{k})$, $\delta_{\mathrm{kj}}$ and $E\left\{V(k) V^{T}(j)\right\}=R(k) \delta_{\mathrm{kj}}$, where, $\delta_{\mathrm{kj}}$ is Keluonike Function: when $k=j,=1$, and when $k \neq j$, $\delta_{\mathrm{kj}}=0$. 
Due to the randomness and uncertainty of disturbance, the variance and mean of noise cannot be determined precisely. In order to estimate the mean $\mathrm{q}(\mathrm{k})$ and variance $\mathrm{Q}(\mathrm{k})$ of control interference noise $\mathrm{W}(\mathrm{k})$ and measure the mean $\mathrm{V}(\mathrm{k})$ and variance $\mathrm{R}(\mathrm{k})$ of measurement noise $\mathrm{V}(\mathrm{k})$, this article will use the maximum posteriori noise estimator sage-husa.

Algorithm steps are as follows:

1) State estimation value in $(\mathrm{k}+1)$ moment;

$\hat{X}(\mathrm{k}+1 \mid \mathrm{k})=\Phi(\mathrm{k}+1 \mid \mathrm{k}) \hat{X}(\mathrm{k} \mid \mathrm{k})+\mathrm{B}(\mathrm{k}) \mathrm{U}(\mathrm{k})+\hat{q}(\mathrm{k})$;

2) Corresponding Covariance of $(\mathrm{k}+1 \mid \mathrm{k}): \mathrm{P}(\mathrm{k}+1 \mid \mathrm{k})=\Phi(\mathrm{k}+1 \mid \mathrm{k}) \mathrm{P}(\mathrm{k} \mid \mathrm{k}) \Phi^{T}(\mathrm{k}+1 \mid \mathrm{k})$ $+\mathrm{Q}(\mathrm{k})$;

3) Kalman gain: $\mathrm{M}(\mathrm{k}+1)=\mathrm{P}(\mathrm{k}+1 \mid \mathrm{k}) \mathrm{H}^{T}(\mathrm{k}) \quad\left[\mathrm{H}(\mathrm{k}) \mathrm{P}(\mathrm{k}+1 \mid \mathrm{k}) \mathrm{H}^{T}(\mathrm{k})+\mathrm{R}(\mathrm{k}+1)\right]$ ${ }^{-1}$;

4) New information in Kalman filter: $\varepsilon(\mathrm{k}+1 \mid \mathrm{k})=\mathrm{y}^{\mathrm{v}}(\mathrm{k}+1)-\mathrm{H}(\mathrm{k}) \hat{X}(\mathrm{k}+1 \mid \mathrm{k})-\hat{r}(\mathrm{k}) ;(9)$

5) Optimal estimation value in $(\mathrm{k}+1)$ moment: $\hat{X}(\mathrm{k}+1 \mid \mathrm{k}+1)=\hat{X}(\mathrm{k}+1 \mid \mathrm{k})+\mathrm{M}(\mathrm{k}+1) \quad \varepsilon \quad(\mathrm{k}+1$ (k) ;

6) $\hat{X}(\mathrm{k}+1 \mid \mathrm{k}+1)$ corresponding covariance: $\mathrm{P}(\mathrm{k}+1 \mid \mathrm{k}+1)=[\mathrm{I}-\mathrm{M}(\mathrm{k}+1) \mathrm{H}(\mathrm{k})] \mathrm{P}(\mathrm{k}+1 \mid \mathrm{k}) ;(11)$

7) Use noise estimator sage - husa to estimate $\omega(\mathrm{k}), \mathrm{Q}(\mathrm{k}), \mathrm{v}(\mathrm{k})$ and $\mathrm{R}(\mathrm{k}) \hat{q}^{\hat{q}}(\mathrm{k})=\left(1-\mathrm{d}^{k}\right)^{\hat{q}}(\mathrm{k}-1)+\mathrm{d}^{k}$ $[\mathrm{X}(\mathrm{k} \mid \mathrm{k})-\Phi(\mathrm{k} \mid \mathrm{k}-1) \mathrm{X}(\mathrm{k}-1 \mid \mathrm{k}-1)-\mathrm{B}(\mathrm{k}) \mathrm{U}(\mathrm{k})]$,

$\mathrm{Q}(\mathrm{k})=\left(1-\mathrm{d}^{k}\right) \mathrm{Q}(\mathrm{k}-1)+\mathrm{d}^{k} \quad\left[\mathrm{M}(\mathrm{k}) \varepsilon(\mathrm{k} \mid \mathrm{k}-1) \varepsilon^{T}(\mathrm{k} \mid \mathrm{k}-1) \mathrm{M}^{T}(\mathrm{k})+\mathrm{P}(\mathrm{k} \mid \mathrm{k})-\Phi(\mathrm{k} \mid \mathrm{k}-1)\right.$ $\left.\mathrm{P}(\mathrm{k}-1 \mid \mathrm{k}-1) \Phi^{T}(\mathrm{k} \mid \mathrm{k}-1)\right]$,

$\hat{r}(\mathrm{k})=\left(1-\mathrm{d}^{k}\right) \hat{r}(\mathrm{k}-1)+\mathrm{d}^{k}\left[\mathrm{y}^{\mathrm{v}}(\mathrm{k})-\mathrm{H}(\mathrm{k}) \mathrm{X}(\mathrm{k} \mid \mathrm{k}-1)\right]$,

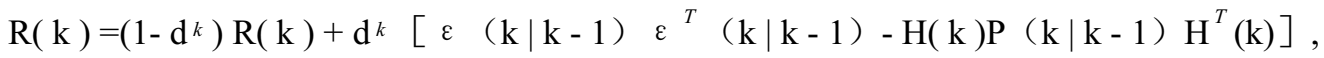

$\mathrm{d}^{k}=(1-\mathrm{b}) /\left(1-\mathrm{b}^{k+1}\right), 0<\mathrm{b}<1$ is forgetting factor, which needs to be determined by experiment, $0.95 \sim 0.99$ is preferable generally[8].

\section{The system simulation results}

The adaptive Kalman filter fuzzy PID control algorithm in this paper is applied to MATLAB2010 for simulation, with UAV platform frame as simulation model, open-loop transfer function is: $\mathrm{G}(\mathrm{s})=16470 /\left(\mathrm{S}^{2}+1667 \mathrm{~S}+3393\right)$; sampling time $\mathrm{t}=1 \mathrm{~ms}$.

Figure 7 is the corresponding membership function:
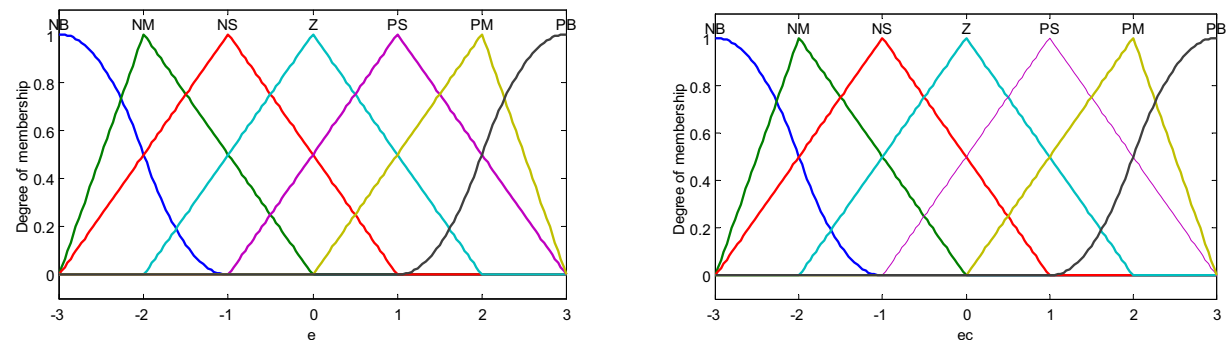

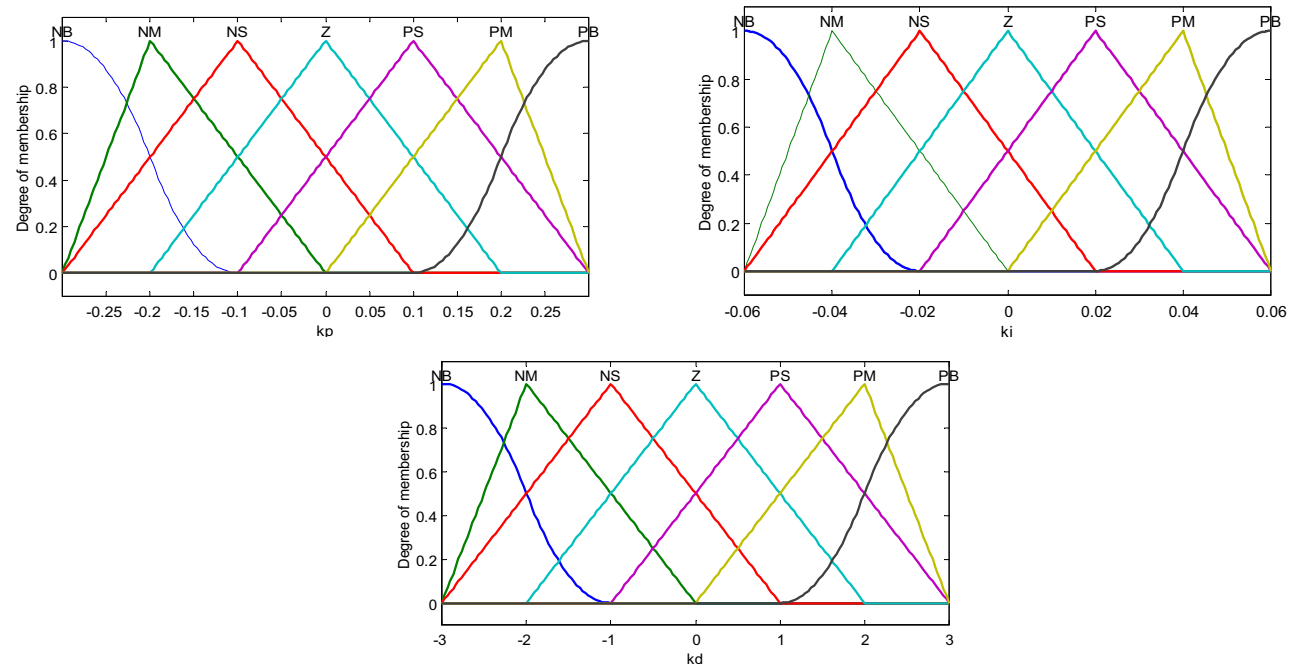

Figure 7: Membership function of fuzzy PID

Step signals are used as the simulation signal for the tests in this article. The comparison of image curves (as shown in figure 8)show that the effects of the performance of classic PID control and fuzzy PID control are inferior to that of fuzzy PID control that based on Adaptive Kalman Filter proposed in this article. Besides, Adaptive Kalman Filter Fuzzy PID control is faster in reaching the steady state and nearly no overshoot is required.

If white noise is added, its amplitude is 0.01 (as shown in figure 9), two algorithms are all interfered largely, fluctuating in the stable value. However by comparison, the algorithm used in this paper can quickly achieve the stable value, with less interference and no overshoot.

The sine wave simulation results show that:

(1) When the white noise with 0.01 amplitude is added, the classic PID and fuzzy PID all have large interference, but the algorithm in this paper can track signals fast and smoothly with no overshoot (as shown in figure10)

(2) when the white noise with 0.10 amplitude, the classic PID and fuzzy PID all have a big deviation and cannot satisfy tracking precision, but the algorithm in this paper still track precisely (as shown in figure11).

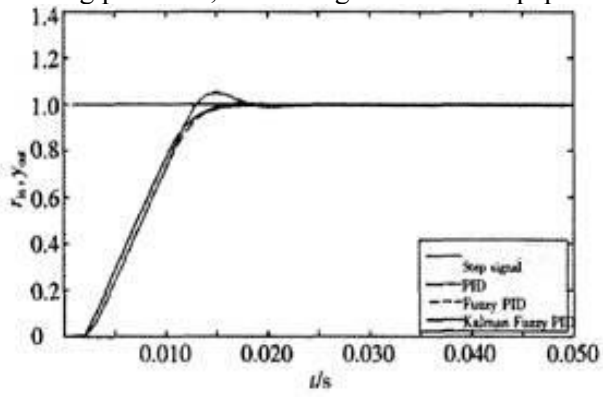

Figure 8: Simulation results of three algorithms for step signal without noise

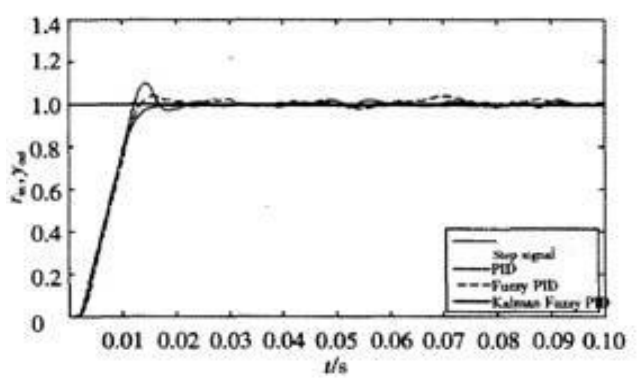

Figure9:Simulation results of three algorithms for step signal with magnitude 0.01 white noise

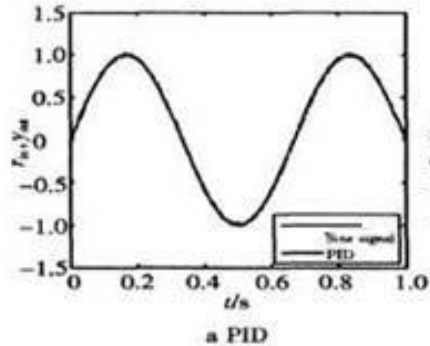

a PID

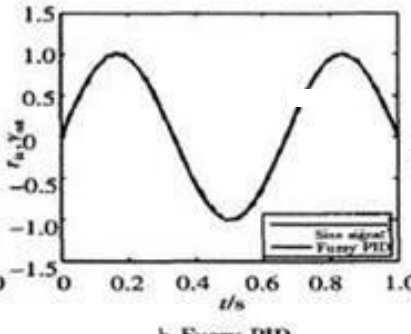

b Fuzzy PID

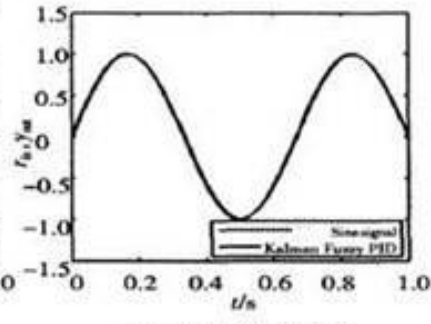

e Kalman Fuzxy PID

Figure 10:Simulation results of three algorithms for sine wave with magnitude 0 . 01 white noise 


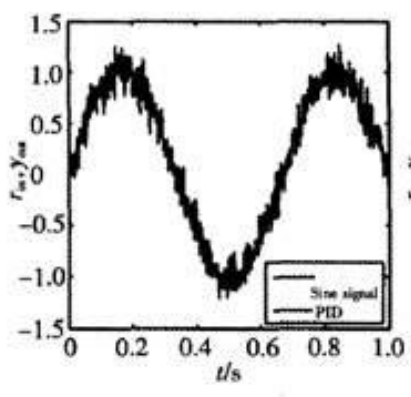

a PID

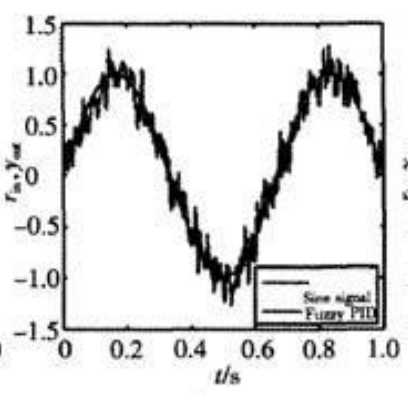

b Fuzzy PID

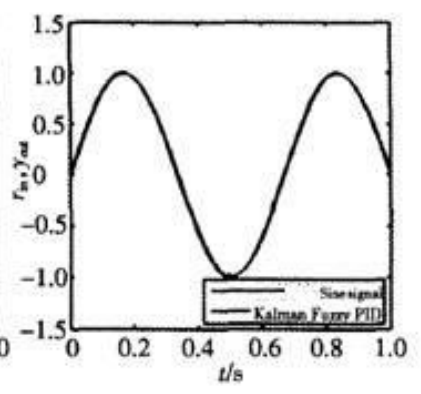

c Kalman Fuzzy PID

Figure 11: Simulation results of three algorithms for sine wave with magnitude 0.1 white noise

\section{Conclusion}

In this article, an UAV power cable patrol system is designed, and a new algorithm of Adaptive Kalman Filter fuzzy PID control is put forward. Under the circumstance of unknown environment parameters and unstable UAV attitude, the algorithm uses infrared sensors to obtain the state of the UAV, so that the platform is controlled. In this way, the platform can precisely track the cable and make it always in the center of UAV, thus the inspection, image transmission and fault detection can be achieved. Theoretical analysis and simulation tests prove the feasibility of this kind of control algorithm. Subsequent research will be the whole set of system tests in practical operation.

\section{Acknowledgements}

The author is highly thankful for the financial support of Practice Innovation Training Projects for College Students in Jiangsu Province in 2015 (No. 201511276001Z), Support Projects of 2016 Challenge Cup Competition from University Students Science and Technology Innovation Fund of Nanjing Institute of Technology (No. TZ20160028) and Major Projects of Innovation Fund of Nanjing Institute of Technology (No. CKJA201606)

\section{References}

1. Zou Ling, Sun Yuqiang and Sun Qi: A Simulation Study of PID Control Based on Kalman filter. Control \& Automation. Vol. 80-81(2007), p. 56

2. Xin Zhekui and Fang Yongchun: Modeling and Control for Tracking Ground Target Using an Unmanned Air Vehicle. Chinese High Techology Letters. Vol. 19(2009), p. 398 - 403

3. Pragasen Pillay: Modeling, Simulation, and Analysis of Permanent-Magnet Drive. IEEE Transactions on Industry Applications. Vol.25(1989), p265 279

4. Liu Jinkun, in: Advanced PID control and MATLAB simulation/Electronic industry publishing house, Beijing(2003), in press.

5. Guo Bingkun, Chen Shuili, Wu Yundong and Li Wei. Fuzzy PID control of three-axis stabilized platform of UAV. JournalofJimeiUniversity(Natural Science)Vol. 73 (2013), p. 309-312

6. Chen Shuili, Li Jianggong and Wang Xianggong, in: Fuzzy set theory and its application/ Science Press, Beijing(2005), in press.

7. Liu Jinkun, in: The 3rd edition of Advanced PID control and MATLAB simulation/ Electronic industry publishing house, Beijing(2011), in press.

8. Ma Jingbo and Yang Honggeng: The Application of Adaptive Kalman Filter in Electric Power System Short-term Load Forecasting. The Grid Technology. Vol. 29 (2005), p75-80 